\title{
The NEMESIS Macro-Econometric Model
}

\author{
Baptiste Boitier, Pierre Le Mouël, Julien Ravet, \\ and Paul Zagamé
}

\subsection{INTRODUCTION}

The NEMESIS model was first used to analyse the impact of the $3 \%$ R\&D objective envisaged in the Lisbon Strategy (Brécard et al., 2004, 2006). This first study was followed by the assessment of the European Commission's National Action Plans related to the Barcelona Objective (Chevallier et al., 2006).

After several other contributions revolving around EU innovation policy strategies, the NEMESIS model has been mainly used for ex-ante impact assessments of the European Research and Innovation Framework Programmes (FPs). In 2005, the NEMESIS model was implemented

Julien Ravet is co-author for section 7.3 on the ex-ante impact of Horizon Europe

B. Boitier · P. Le Mouël · P. Zagamé SEURECO/ERASME, Paris, France

J. Ravet $(\bowtie)$

European Commission, DG RTD, Brussels, Belgium

e-mail: julien.ravet@ec.europa.eu

(C) The Author(s) 2022

U. Akcigit et al. (eds.), Macroeconomic Modelling of R\&D

and Innovation Policies, International Economic Association Series, https://doi.org/10.1007/978-3-030-71457-4_7 
for the ex-ante assessment of the $7^{\text {th }}$ FP (Delanghe \& Muldur, (2007; European Commission, 2005) and thereafter for the Horizon 2020 Programme (European Commission, 2012). From 2010 to 2013, the NEMESIS model supported the annual ex-ante assessment of the $7^{\text {th }}$ FP calls for proposals (Fougeyrollas et al., 2010, 2011; Zagamé, 2010; Zagamé et al., 2012).

More recently, NEMESIS has been significantly improved by enlarging the innovation mechanisms captured besides $\mathrm{R} \& \mathrm{D}$ investments. In particular, investments in Information and Communication Technologies (ICT) and in intangible assets other than R\&D (mainly software and training) have been incorporated. This enhances the assessment of R\&I policies, by including some of the most up-to-date theoretical as well as empirical findings in the field (Le Mouël et al., 2016). This new version of NEMESIS has been used for the ex-post assessment of the $7^{\text {th }}$ FP and the interim assessment of the Horizon 2020 programme (European Commission, 2017b; PPMI, 2017). It has also been used to simulate the socioeconomic and environmental impact assessment of the future 2021-2027 EU R\&I Programme, Horizon Europe (Boitier et al., 2018).

The chapter is divided in two parts. The first provides a description of the NEMESIS model with a strong focus on its innovation mechanisms. The second part provides an example of the implementation of the model, by summarising the results of the recent work carried out with the model in the context of the impact assessment of the Horizon Europe programme (European Commission, 2018).

\subsection{The ModeL}

The NEMESIS model differs from the rest of the models presented in this book, in which behavioral equations are directly derived from optimality condition. Being a macro-econometric model, in NEMESIS the short to medium term dynamics are influenced by several factors that keep the economic agents out of the optimal paths. These include adjustment costs, sticky prices, and adaptive expectations, governed by error correction mechanisms for ensuring convergence to the long term equilibrium. Furthermore, the capital market is not explicitly modeled in NEMESIS, which precludes the attainment of a general equilibrium, even in the long term. The notion of equilibrium in this type of models refers instead to a stable state where some of the markets modelled can permanently be out of equilibrium. 
Regarding innovation, the model features the following important properties to analyse innovation policy:

- Heterogeneity of economic sectors in many dimensions, including: investments in innovative assets, energy consumption, environmental externalities, capital-labour ratios, qualification requirements.

- Sectoral dynamics and related interdependencies, including knowledge spillovers that allow knowledge to be diffused across sectors and countries.

- Long-term economic growth properties as in the seminal theoretical formulation of the fully endogenous approach initiated by Aghion and Howitt (1998). Under this formulation, the long-term rate of economic growth is an increasing function of R\&D intensity, and can thus be influenced by policy.

- Distinction between process and product innovation, with dissimilar impacts on the economy.

- Presence of intangible assets other than R\&D (training and software) and ICT assets, which allow a more realistic representation of the innovation mechanisms, particularly in the services sectors.

In what follows, we first present the general characteristics of the model, and then its innovation and endogenous growth properties. We finish by presenting an application of the model to the ex-ante socioeconomic impact assessment of the future EU R\&I programme: Horizon Europe.

\subsubsection{Geneval Overview of NEMESIS}

The NEMESIS model is a detailed sectoral macro-econometric model estimated for every country of the EU. ${ }^{1}$ It distinguishes between 30 sectors operating within five-level nested-CES functions. The model covers both the supply and demand sides of the economy, and incorporates endogenous technical change. The conversion matrices of the model for final consumption, investment goods, intermediate consumption,

1 The model's development has been financed by different European Framework Programmes and has been coordinated by the ERASME team that became SEURECO. 
energy/environment and technological transfers, capture the interdependencies between production sectors (with one representative firm per sector) and between producers and other agents in the economy, namely households, the government and foreign countries. Every country model includes an economic core that can be simulated in interaction with a detailed energy/environment module. Simulation of policy effects can be carried out for an individual country or for all countries simultaneously.

\subsubsection{Model's Structure}

The NEMESIS model uses several datasets that are compiled, harmonized and complemented to feed the model in a manner that fits its structure. ${ }^{2}$

Two types of equations are at play in NEMESIS: (i) the accounting equations, reflecting the system of national accounts, and (ii), the behavioral equations, which capture, based on both theoretical and empirical grounds, how economic agents operate. The latter include longterm structural equations featuring an error correction mechanism that captures convergence towards the variables' long term values. The key elasticity parameters of behavioral equations are either estimated using panel data techniques, or calibrated based on consensus values arising from the relevant literature.

On the supply side, each sector is modeled with a representative firm that makes decisions regarding output and the use of factors, given expectations on demand and input prices. Firms produce output according to five-level nested-CES production functions, employing the following inputs: low-skilled labour, high-skilled labour, capital, energy and intermediate consumption. In addition, firms include innovation in their invesment decisions to improve their productivity and/or their products, implying that technical progress is endogenously determined in the model. Innovation is the result of investments in three types of assets: R\&D, ICT and Other Intangibles (including software and training). The specification of the innovation process in the model allows to account for a large range of innovative activities, including ICT, which are considered a general purpose technology (GPT). Furthermore, while R\&D

2 The data sources include National Accounts (Eurostat, 2018a), Labour Force Surveys (Eurostat, 2018c), Annual Sectors Accounts (Eurostat, 2018b), WIOD (Timmer et al., 2015), statistics on research and development (Eurostat, 2018d) and OECD (2017) statistics on intangible investments and assets (Corrado et al., 2014) and statistics on taxation (European Comission, 2017). 
investments are central in industrial sectors, the other types of innovation assets capture more appropriately the process of innovation in the service sectors. Finally, interdependencies between sectors and countries are captured by a collection of matrices describing the exchanges of intermediary goods and capital goods as well as the flows of knowledge spillovers.

Firms are monopolistically competitive, so that in the long-term markups are constant, albeit different between sectors. Wages are determined via an augmented Phillips curve in which the growth rate of wages is a function of the unemployment rate, labour productivity and consumption prices. Since the model features two types of labour (low-skilled and highskilled), there exist two such equations for wage determination.

On the demand side, the representative household determines its aggregate consumption as a function of its disposable income arising from wages, capital income and social transfers. Child and old-age dependency rates are also included to capture changes in consumption patterns caused by changes in the structure of the population. The unemployment rate is used, in the short term, as a proxy for the perceived degree of uncertainty in the economy. Total aggregate household consumption is split into 27 different consumption sub-functions capturing relative prices, substitution elasticities and the specific nature of the products (e.g., durable/non durable).

The are two type of trade flows in NEMESIS: intra-EU and trade with the rest of the world. Exports are driven by both an income effect, which captures demand arising from other regions, and a price effect, which captures relative competitiveness with respect to other EU-countries and the rest of the world. Exports are also influenced by structural competitiveness due to quality-adjusted prices, on which all the demand functions are based. For imports, the drivers are similar: the income effect is captured by internal demand, and the price effect by the ratio between the import price and the price of domestic producers.

\subsubsection{Model's Main Mechanisms}

The general functioning of the model is shown in Figure 7.1.

As most macro-econometric models, which are based on national accounting, NEMESIS is by construction governed by aggregate demand in the short to medium term. Feedback effects, however, exist between demand and supply conditions that finally determine prices and quality of products. As illustrated in the next section later, the link between R\&D 


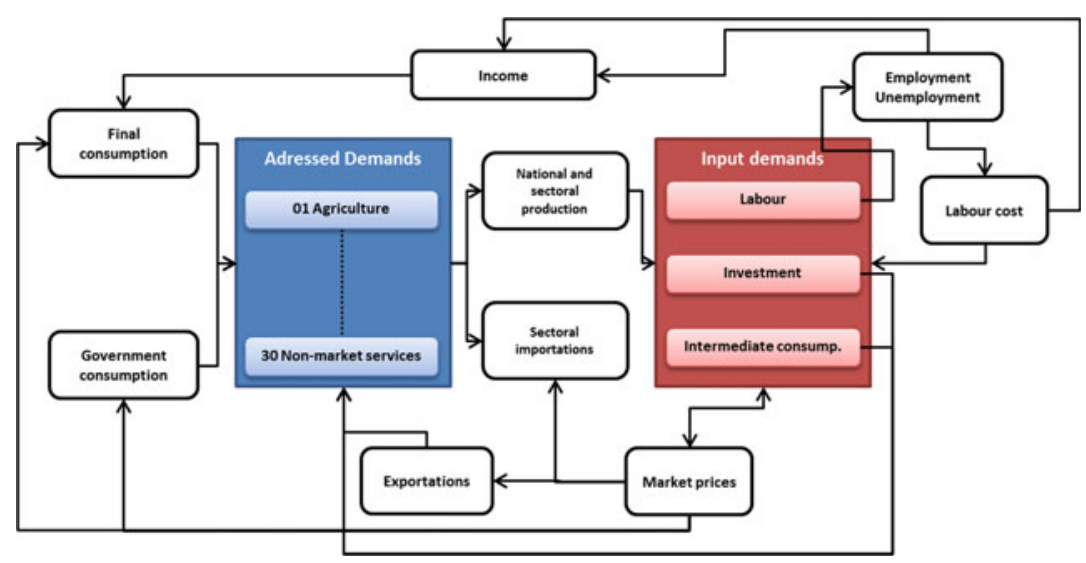

Fig. 7.1 NEMESIS basic structure

investments and economic growth is based in the model on the new endogenous growth theory, where it is possible to increase productivity growth by increasing R\&D intensity. The implication of this is that the long term economic growth rate can be modified, bringing the model away from its core Keynesian features and closer to the Schumpeterian paradigm.

The starting point of the economic dynamics in NEMESIS arises from a shock to some of the exogenous variables: demographic, world demand, exchange and interest rates, world commodity prices (including fossil fuels prices) and internal policy rules. The dynamics are recursive and based on three main elements: (i) state variables (stocks), (ii) adaptive expectations and adjustment lags, and (iii) adjustment processes to each variable's optimal level.

There are two types of stock variables, namely physical capital and knowledge. Regarding the former, there is a maturation lag of one year to transform investments into operational capital. On the other hand, knowledge is generated through investment flows in R\&D, ICT and other intangibles (OI), with maturation lags of two years for public R\&D and one year for private R\&D, ICT and OI. The transformation of knowledge into innovation is also progressive and affected by sector-specific lags. All these delays are important for the assessment of innovation support policies, which take about 15 years for their full impact to take place. 
The model's dynamic can also be analyzed from the perspective of the different levels of granularity embedded in the model. For example, in the case of an increase in $\mathrm{R} \& \mathrm{D}$ expenditure, the impact mechanisms in the model can be traced as follows:

- At sectoral level, an increase competitiveness, output and employment.

- At inter-sectoral level, an increase in transaction flows and knowledge spillovers.

- At the aggregate level, the general equilibrium impact on variables such as wages, consumption and savings of the previous effects, are also captured.

Hence, there are three main layers of economic indicators: (i) macroeconomic, such as GDP and its components (final consumption, gross fixed capital formation, exports, imports, etc.), unemployment rates, etc.; (ii) sectoral, such as output, value added and employment per sector, and (iii) those related to national agent accounts: government, non financial corporations, financial corporations, households, and the external sector. Beyond economic indicators, the NEMESIS energy-environment module also captures results on energy supply and demand by fuel type and technology, and on $\mathrm{CO}_{2}$ emissions.

\subsubsection{Supply Block and Innovation Mechanisms}

Next, to provide a clear description of the mechanisms at play in the model when simulating innovation policy shocks, we examine the specific sectoral production functions, followed by a detailed discussion of the innovation flows, which are one of the inputs into these production functions.

\subsubsection{The Nested CES Production Function Framework}

Figure 7.2 illustrates the nested nature of the production functions used. In each sector, output (in yellow) results from the combination of four variable inputs (in green) and two quasi-fixed inputs (in red). The variable inputs are materials $(M)$, energy $(E)$, lowly qualified labour $\left(L_{L}\right)$ 


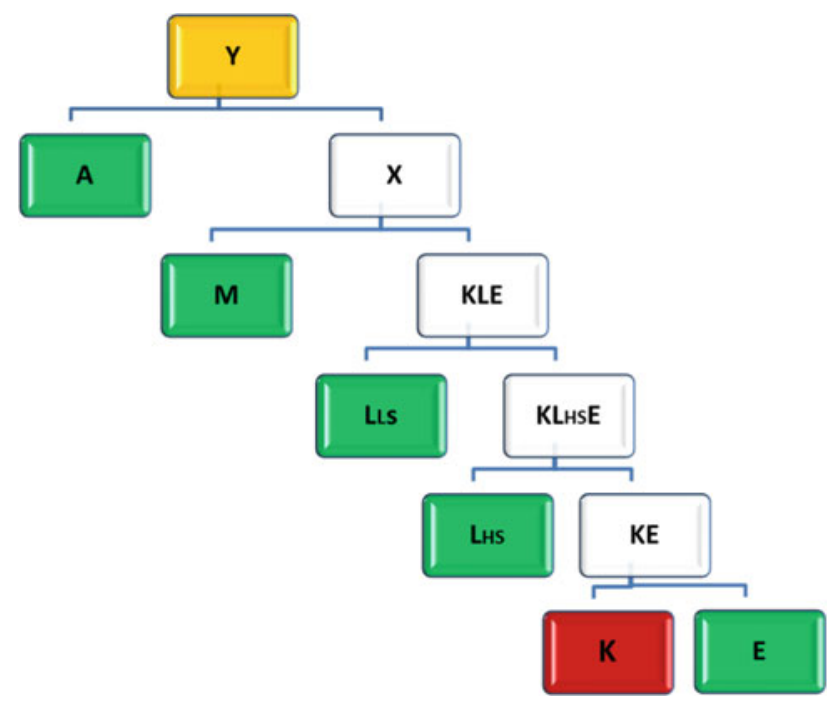

Fig. 7.2 The nested CES production function

and highly qualified Labour $\left(L_{H}\right)$ (ISCED 5 and 6). ${ }^{3}$ Quasi-fixed inputs are physical capital stock $(K)$ and innovation services $(A)$. The other inputs (in white) are the compound inputs - or 'intermediate outputs'corresponding to the different levels of the nested CES function.

In the current version of the nested production function, innovation services enter at the first level, meaning that they proportionally increase marginal productivity of ordinary production factors, represented by the variable $X$ that groups together the physical capital stock, the two categories of labour, and energy and materials. The impact of innovation on the production function is consequently Hick's neutral as it does not affect the balance between production factors.

This first level of the nested production function has the following analytical expression:

$$
Y=C \cdot\left[\delta_{A}^{1+\rho_{Y}} A^{-\rho_{Y}}+\delta_{X}^{1+\rho_{Y}} X^{-\rho_{Y}}\right]^{-\frac{1}{\rho_{Y}}}
$$

${ }^{3}$ Low and high labour qualifications correspond to ISCED levels $1-4$ and 5-6, respectively. 
where $C$ is a scale parameter, $\delta_{A}$ is the share parameter for $A$, representing the share of innovation services in total output, $\delta_{X}$ is likewise the share parameter for $X$ (by definition $\delta_{X}=1-\delta_{A}$ ), and $\rho_{y}$ is the parameter that determines the partial elasticity of substitution between innovation services and $X$, equal to $\sigma_{Y}=\frac{1}{1+\rho_{Y}}$.

The functional forms of the other levels of the nested production functions are symmetric, and thus the the definition of factor shares are analogous.

\subsubsection{Innovation Mechanisms}

In the new version of the NEMESIS model, the flow of innovations in the different sectors and countries, do not result any more only from public and private R\&D investments, but also from investments in ICT and in two categories of intangible other than $\mathrm{R} \& \mathrm{D}$, namely training and software. ${ }^{4}$ As in previous vintages (Brécard et al., 2006), the model distinguishes between product and process innovations.

The theoretical approach builds on the semi-endogenous and fully endogenous growth theory (Ha \& Howitt, 2007). This approach has been adapted to be bridged with the concept of ICT as general purpose technology, as proposed by Bresnahan and Trajtenberg (1995). In this new framework, there are sources of externalities other than investments in $\mathrm{R} \& \mathrm{D}$. In particular, externalities can also arise from the interactions between: (1) producers and users of ICT, (2) ICT users' co-inventions, and (3) ICT users' investments in complementary intangible assets.

In practice, these modifications affect the model in two main ways: (1) the modification of the innovation functions in the different sectors (now three dimensional), and (2) the modeling of knowledge externalities relative to different innovation assets. The calibration was based on existing empirical studies on the impacts of R\&D, ICT and other intangibles (OI) investments on productivity and employment, at the macro, sectoral and micro levels (see Le Mouël et al., (2016). This new version of the model permits a more precise representation of innovation dynamics in the service sectors. It thus enlarges considerably the range of R\&I policies whose macroeconomic impacts can be assessed with the model.

\footnotetext{
4 This new version was first used in 2017 to support the ex-post assessment of FP7 and the interim evaluation of the Horizon 2020 Framework Programme (see (European Commission, 2017b; PPMI, 2017).
} 


\section{Three dimensional innovation functions}

The flow of innovations in sector $i$ in country $c, A_{\text {cit }}$, is a CES combination of three sub-innovations, denoted as innovation components, which are, in turn, investments in $\mathrm{R} \& \mathrm{D},\left(A R_{c i t}\right)$, investments in ICT, $\left(A T_{c i t}\right)$, and investments in OI, $\left(A I_{c i t}\right)$. The algebraic expression for the production function of innovation flows is:

$$
\begin{aligned}
A_{c i t}= & S C_{A c i} \cdot\left[\delta_{A R c i}^{1+\rho_{A c i}} A R_{c i t}-\rho_{A c i}\right. \\
& \left.+\delta_{A T c i}^{1+\rho_{A c i}} A T_{c i t}-\rho_{A c i}+\delta_{A I c i}^{1+\rho_{A c i}} A I_{c i t}-\rho_{A c i}\right]^{-\frac{1}{\rho_{A c i}}}
\end{aligned}
$$

where $S C_{A c i}$ is a scale parameter, $\delta_{A R c i}, \delta_{A T c i}$ and $\delta_{A I c i}$ are distribution parameters and $\rho_{A c i}$ determines the elasticity of substitution between $A R_{c i t}, A T_{c i t}$ and $A I_{c i t}, \sigma_{A c i}=\frac{1}{1+\rho_{A c i}}$.

In turn, production of the three innovation components is governed by the following expression:

$$
A j_{c i t}=S C_{A j c i} \cdot K N O W j_{c i t}^{\lambda j i \cdot \frac{j_{c i t}}{V A_{c i t}}}
$$

where $j=R, T, I$, and $S C_{A j c i}$ are scale parameters.

They are positive functions of a sector-country specific knowledge stock, $K N O W j_{c i t}$, and of a specific knowledge absorption capability, $\lambda_{j} \cdot \frac{j_{c i t}}{Y_{c i t}} .{ }^{5}$ This knowledge absorption capability is, with $\lambda_{j}>0$, a linear positive function of the investment intensities in R\&D, ICT or OI.

\section{Knowledge stocks: The role of knowledge spillovers}

Knowledge stocks, $K N O W j_{c i t}$, are modeled as weighted sums of the stocks of assets (R\&D, ICT, OI) across all sectors and countries. ${ }^{6}$

For all three innovation components, knowledge in sector $i$ of country $c, K N O W R_{c i t}$, is defined as the sum of the innovation component capital stocks $S R_{p, s, t-\Delta}$ from all country-sector pairs $(p, s)$, weighted by a coefficient of diffusion $\Psi_{p, s \rightarrow c, i}$. This coefficient captures the relative

5 This functional specification represents a departure from the related literature, where the elasticity of the flow of ideas with respect to the knowledge stock is commonly assumed to be a calibrated or estimated constant, rather than an object endogenously determined by investment intensity.

6 The depreciation rates used come from Corrado et al. (2012). These are 0.15 for $\mathrm{R} \& \mathrm{D}, 0.315$ for ICT, 0.315 for software and 0.4 for training. 
propensity of knowledge from sector $s$ in country $p$ to be useful to innovate in sector $i$ in country $c .^{7}$ It is also assumed that investments start producing knowledge after a delay $\Delta$ (two years). In algebraic terms,

$$
K N O W j_{c, i, t}=\sum_{p, s} \Phi_{p, s-c, i} \times S j_{p, s, t-2} \quad \forall \quad j \in R, T, I
$$

Public investments in R\&D (PIRD) are allocated towards the different sectors in proportion to the share of each sector in overall business $R \& D$ expenditure. ${ }^{8}$

\section{Process and product innovation}

In NEMESIS, innovations cannot, by assumption, be exchanged on a market. They are not an asset that can be capitalized, but rather a flow of services that is produced according to equation 7.2 above. ${ }^{9}$ Two effects of innovations can be distinguished in the model:

- From equation 7.1, the first level of the nested CES production function, 'process innovations' decrease the ex-ante use of $X_{c i t}$, the compound input for ordinary production factors per unit of output, with an elasticity $\alpha_{c i}$;

- 'Product innovations', on the other hand, also increase, ex-ante, the quality of products, with an elasticity $\alpha_{c i}^{\prime}$, but without decreasing the use of $X_{\text {cit }}$ per unit of output.

This distinction between product and process innovation is central for at list two reasons. On the one hand, in most empirical studies, private returns to process $\mathrm{R} \& \mathrm{D}$ have been shown to be higher than for product

\footnotetext{
7 Diffusion parameters are calibrated on patent citations between sectors and countries, following the methodology developed by Verspagnen (1997). See also Belderbos and Mohnen (2013) for more details.

${ }^{8}$ In addition, public R\&D investments are considered to be productive after a longer lag than private R\&D (2 years later).

${ }^{9}$ Innovations are also supposed to begin producing their effects after a delay of one year.
} 
R\&D. ${ }^{10}$. As reported by Hall et al. (2010), there exist several explanations. For instance, product innovations often involve a "start-up and debugging phase" that reduce their returns in the short run. Additionally, the measurement of product R\&D effects are difficult because of the currently poor translation of of quality improvements into changes in price indices, which is especially true for the goods and services produced by the public sector. On the other hand, output and employment impacts of product and process innovations are also dissimilar. Hall (2011) shows that the impact of product innovations on firms' revenue growth is always positive, while the impact of process innovations is small or even negative. They also found similar results on the impacts of these two types of innovations on employment. In particular, Peters et al. (2014) show that the employment impacts of process and organizational innovations are smaller than the ones of product innovations. Focusing on the distinct impacts of innovations on employment in service industries, Damijan et al. (2014) conclude that empirical studies generally find a positive impact of product innovations, and a negative impact of process innovations, while no major differences between manufacturing and services seem to emerge from the literature. $^{11}$

Algebraically, these elasticities read:

$$
\begin{aligned}
\alpha_{c, i} & =\frac{\partial \ln \left(X_{t}\right)}{\partial \ln \left(A_{t}\right)} \\
\alpha_{c, i}^{\prime} & =\frac{\partial \ln \left(D_{t}\right)}{\partial \ln \left(A_{t}\right)}
\end{aligned}
$$

where $D_{t}$ is the demand faced by the representative firm.

In addition, it is assumed that in each sector the quality of output evolves in proportion with process innovation: $\alpha_{c i t}^{\prime}=m_{c i} \alpha_{c i t}$.

\subsubsection{Endogenous Growth Properties}

This sub-section analyzes in more detail the endogenous growth properties resulting from the innovation mechanisms of the model. For that,

${ }^{10}$ Hall et al. (2010) quote several studies in this respect: Clark and Griliches (1984), Griliches and Lichtenberg (1984), Link (1982), Terleckyj (1980), Scherer (1982, 1983), and Hanel (1994)

${ }^{11}$ See also Harrison et al. (2014) and Bogliacino and Pianta (2010). 
let us start by obtaining the expression for the long term growth rate of sectoral output. By differentiating the equation for sectoral output (Eq.7.1) expressed in natural logarithms with respect to time, we obtain:

$$
\frac{d \ln \left(Y_{c i t}\right)}{d t}=\varepsilon_{A_{c i t}}^{Y_{c i t}} \cdot \frac{d \ln \left(A_{c i t}\right)}{d t}+\varepsilon_{X_{c i t}}^{Y_{c i t}} \cdot \frac{d \ln \left(X_{c i t}\right)}{d t}
$$

where:

$$
\begin{aligned}
& \varepsilon_{A_{c i t}}^{Y_{c i t}}=\frac{\partial \ln \left(Y_{c i t}\right)}{\partial \ln \left(A_{c i t}\right)}=S C Y_{c i}^{-\rho Y_{c i}} \cdot \delta A_{c i}^{1+\rho Y_{c i}} \cdot\left(\frac{Y_{c i t}}{A_{c i t}}\right)^{\rho Y_{c i}} \\
& \varepsilon_{X}^{Y_{c i t}}=\frac{\partial \ln \left(Y_{c i t}\right)}{\partial \ln \left(X_{c i t}\right)}=S C Y_{c i}^{-\rho Y_{c i}} \cdot \delta X_{c i}^{1+\rho Y_{c i}} \cdot\left(\frac{Y_{c i t}}{X_{c i t}}\right)^{\rho Y_{c i}}
\end{aligned}
$$

are the elasticities of sectoral output with respect to innovations services, $(A)$, and the bundle of traditional production inputs, $(X)$, respectively.

The long term growth of sectoral output can therefore be decomposed in two components:

1. An endogenous one, driven by the growth of innovation services:

$$
\frac{d \ln \left(Y_{c i t}^{A}\right)}{d t}=\varepsilon_{A_{c i t}}^{Y_{c i t}} \cdot \frac{d \ln \left(A_{c i t}\right)}{d t}
$$

2. An exogenous one, driven by the growth of traditional production factors:

$$
\frac{d \ln \left(Y_{c i t}^{E}\right)}{d t}=\varepsilon_{X_{c i t}}^{Y_{c i t}} \cdot \frac{d \ln \left(X_{c i t}\right)}{d t}
$$

Hence,

$$
\frac{d \ln \left(Y_{c i t}\right)}{d t}=\frac{d \ln \left(Y_{c i t}^{A}\right)}{d t}+\frac{d \ln \left(Y_{c i t}^{E}\right)}{d t}
$$

It follows from equation (7.11) that the endogenous growth rate of sectoral output can be assimilated to a 'pure' TFP effect. We can thus write:

$$
\frac{d \ln \left(Y_{c i t}^{A}\right)}{d t}=\frac{d \ln \left(T F P_{c i t}\right)}{d t}=\frac{d \ln \left(Y_{c i t}\right)}{d t}-\frac{d \ln \left(Y_{c i t}^{E}\right)}{d t}
$$


or equivalently:

$$
\frac{d \ln \left(T F P_{c i t}\right)}{d t}=\frac{d \ln \left(Y_{c i t}\right)}{d t}-\varepsilon_{X_{c i t}}^{Y_{c i t}} \cdot \frac{d \ln \left(X_{c i t}\right)}{d t}
$$

According to the latter, growth in TFP, which captures the slack between the growth of output and the growth of traditional production factors, can be explained by endogenous investments in innovation inputs and the accompanying knowledge externalities. In practice, the TFP indexes that are computed from national account data lump together the joint influence of many mechanisms.

By keeping $Y_{\text {cit }}$ constant in equation 7.1 , we can define the 'TFP effect' as minus the elasticity of demand of production inputs with respect to innovations services, as follows:

$$
\alpha_{c i t}=-\frac{\partial \ln \left(X_{c i t}\right)}{\partial \ln \left(A_{c i t}\right)}=\frac{\varepsilon_{A}^{Y_{c i t}}}{\varepsilon_{X}^{Y_{c i t}}}
$$

This 'TFP effect' is different from the definition given in equation 7.13 and must be interpreted as a measure of the transformation of the set of production possibilities resulting from the growth of innovation services over time, for a given level of output.

The second channel via which innovations services affect output growth is linked to the increase in the demand faced by firms arising from the gradual improvement of the characteristics of their products. This 'Quality effect' is defined as:

$$
\frac{d \ln \left(Q_{c i t}\right)}{d t}=\alpha_{c i t}^{\prime} \cdot \frac{d \ln \left(A_{c i t}\right)}{d t}
$$

In each sector, the quality of output is assumed to evolve in time proportionally to the 'TFP effect' (with a coefficient $m_{c i}$ ), so that:

$$
\alpha_{c i t}^{\prime}=m_{c i} \cdot \alpha_{c i t}
$$

In NEMESIS, these two distinct innovation effects act on the sectoral output of firms through the price elasticity of demand, $\varepsilon_{c i t}^{D}<0$. In particular, 
1. Process innovations reduce the unit costs with an elasticity $\alpha_{c i t}$, which leads to a proportional reduction in prices charged by firms, implying in turn an increase in demand with elasticity $-\varepsilon_{c i t}^{D} \cdot \alpha_{c i t}$.

2. Product innovations increase demand directly, according to an elasticity $-\varepsilon_{c i t}^{D} \cdot \alpha_{c i t}^{\prime}$

In equilibrium, the level of output must be equal to the level of demand, and thus the 'endogenous' part of output growth, which results from the growth of investment in the different types of innovation, $\frac{d \ln \left(Y_{c i t}^{A}\right)}{d t}$, is equal to:

$$
\begin{aligned}
\frac{d \ln \left(Y_{c i t}^{A}\right)}{d t}= & \left(-\varepsilon_{c i t}^{D} \cdot \alpha_{c i t}-\varepsilon_{c i t}^{D} \cdot \alpha_{c i t}^{\prime}\right) \cdot \frac{d \ln \left(A_{c i t}\right)}{d t} \\
& =-\varepsilon_{c i t}^{D} \cdot\left(1+m_{c i t}\right) \cdot \alpha_{c i t} \cdot \frac{d \ln \left(A_{c i t}\right)}{d t}
\end{aligned}
$$

This 'endogenous' growth rate of sectoral output, encompasses three combined effects that go beyond the pure TFP effect in equation 7.14:

1. A TFP effect through the elasticity $\alpha_{c i t}$;

2. A quality effect through the elasticity $\alpha_{c i t}^{\prime}=m_{c i} \cdot \alpha_{c i t}$;

3. A demand effect through the elasticity $\varepsilon_{c i t}^{D}$.

A further decomposistion can be made in order to investigate the distinct contributions of the three innovation components on the long term endogenous growth rate. To do so, we start by differentiating equation 7.2 for innovation services, with respect to time:

$$
\frac{d \ln \left(A_{c i t}\right)}{d t}=\sum_{j} \varepsilon_{A j_{c i t}}^{A} \cdot \frac{d \ln \left(A j_{c i t}\right)}{d t}, j=R D, I C T, O I
$$

with:

$$
\varepsilon_{A j_{c i t}}^{A}=S C A_{c i}^{-\rho A_{c i}} \cdot \delta A j_{c i}^{1+\rho A_{c i}} \cdot\left(\frac{A_{c i t}}{A j_{c i t}}\right)^{\rho A_{c i}}
$$

By assuming that the investment rates of innovation assets (in \% of output) at sectoral level are constant in the long term, the growth rates of innovation components can be further decomposed from equation 7.3 as 
follows:

$$
\frac{d \ln \left(A j_{c i t}\right)}{d t}=\lambda_{j c i} \cdot \frac{j_{c i t}}{Y_{c i t}} \cdot \frac{d \ln \left(K N O W j_{c i t}\right)}{d t}
$$

By substitution of 7.20 into 7.18 :

$$
\frac{d \ln \left(A_{c i t}\right)}{d t}=\sum_{j} \varepsilon_{A j_{c i t}}^{A} \cdot \lambda_{j c i} \cdot \frac{j_{c i t}}{Y_{c i t}} \cdot \frac{d \ln \left(K N O W j_{c i t}\right)}{d t}, j=R D, I C T, \quad O I
$$

And by substitution of 7.21 into 7.17 :

$$
\begin{gathered}
\frac{d \ln \left(Y_{c i t}^{A}\right)}{d t}=-\varepsilon_{c i t}^{D} \cdot\left(1+m_{c i}\right) \cdot \alpha_{c i t} \cdot \sum_{j} \varepsilon_{A j_{c i t}}^{A} \cdot \lambda_{j c i} \cdot \frac{j_{c i t}}{Y_{c i t}} . \\
\frac{d \ln \left(K N O W j_{c i t}\right)}{d t}, j=R D, I C T, O I
\end{gathered}
$$

The implications of equation 7.22 on the properties of the growth rate in output are:

- First, there is no endogenous growth in NEMESIS without growth in knowledge externalities. From a theoretical perspective, this property links the modeling of innovations in the model to the semiendogenous growth literature where the ultimate source of growth is the size of the stock of R\&D, which benefit from knowledge externalities. This property of the semi-endogenous growth models was simply extended in NEMESIS to sources of externalities other than $\mathrm{R} \& \mathrm{D}$. The implication of this is that growth in the model is strongly dependent on the assumptions made on the growth of knowledge externalities. In the business-as-usual scenarios, it is assumed that the investment rates of the innovation assets stay constant in the medium to long term, and that growth in knowledge follows the growth of economic activity in the different world regions.

- Second, the long term endogenous growth rate is an increasing, but bounded, function of the investment rates in innovation assets, which can be influenced by policy instruments.

- Third, from the previous two points, policies aimed at increasing innovation, such as the EU's R\&I programmes, affect the long term endogenous growth rate in the model through two channels: 
1. An intensity effect, by raising the ability of firms to exploit existing knowledge

2. A knowledge effect, by which the creation of new knowledge increases the intrinsic productivity of innovation inputs.

\subsection{An EXample: Simulating THE EX-ANTe Impact of Horizon Europe}

\subsubsection{Context of the assessment}

The NEMESIS model has been used for several socio-economic impact assessments of European R\&I support policies and mainly for ex-ante studies, but also in ex-post analysis PPMI (2017) and European Commission (2017b). Recently, the model has also supported the socio-economic and environmental impact assessments of the future EU R\&I Programme: Horizon Europe. We present here two of the four batches of policy options assessed with the NEMESIS model. ${ }^{12}$

For the simulation of the expected impacts of the Horizon Europe programme, the following scenarios were considered:

1. The "Continuation" scenario in which Horizon 2020, the previous programme, continues for the next multi-annual financial framework (2021-2027). This is compared with a scenario without EU R\&I programme after 2020.

2. And a set of alternative scenarios on the design of the future Horizon Europe and regrouped in two scenarios called "more impact" and "more openness". These are compared with the "Continuation" scenario.

Starting with the description of the methodology used for the socioeconomic impact assessment of Horizon Europe conducted with the NEMESIS model, we proceed with the presentation of the main macroeconomic results for the "Continuation", followed by two other scenarios on the design options of Horizon Europe, namely "more impact" and "more openness".

12 The contents of this section draw primarily from Annex 5 in European Commission (2018). For an in-depth analysis, see Boitier et al. (2018). 


\subsubsection{Implementation of Horizon Europe in the Model}

Before running the model, we must define two different sets of variables or parameters. The first set of variables for the implementation of the Horizon Europe programme in NEMESIS is related to budget allocations, not only the overall amount and its temporal allocation, but also the decomposition between 'basic' and 'applied' research, as well as geographical and sectoral allocations. The second set of important factors for the analysis of EU R\&I policy is related to the innovation mechanisms. The original parameters have been calibrated based on the empirical literature (Le Mouël et al., 2016). In order to assess any EU R\&I programme, the key challenge is to evaluate how these parameters need to be modified when research activities are carried out at the European-wide level. The essential parameters are: (i) the leverage or direct crowding-in effect, giving the increase in private $\mathrm{R} \& \mathrm{D}$ expenditures following a one euro subsidy, (ii), the knowledge spillovers and, (iii), the economic performance of research. As a specific re-calibration of the knowledge spread parameters for EU R\&I programmes is currently unfeasible, the ones currently present in the model are used, and for the case of different knowledge spillovers stemming from Horizon Europe, it is assumed that part of European-wide knowledge spillovers can be assimilated to a modification of the economic performance parameters.

\subsubsection{Key Assumptions Behind the Impact Assessment Exercise}

As touched upon before, the key assumptions in NEMESIS for assessing the impact of the Framework Programme are related to budget size, budget allocation and the value of key parameters such as leverage and economic performance. Table 7.1 shows the main assumptions behind the "Continuation" of $\mathrm{H} 2020$ :

In this "Continuation" scenario, the budget size and its allocation are assumed to be the same as in Horizon 2020 in constant prices, minus the contribution from the UK (assumed to be $15 \%$ of the budget). The Horizon Europe programme is assumed to be financed through a reduction in national public investment. Regarding the direct leverage effect, the assumptions used are supported by a survey on research units involved in the $7^{\text {th }}$ Framework Programme and by a body of empirical literature. A sensitivity analysis shows that the former parameter does not significantly drive the results produced by this impact assessment, for the values used in this study. Economic performance in NEMESIS is calibrated 
Table 7.1 Key assumptions for the "Continuation" scenario (continuation of Horizon 2020)

\begin{tabular}{|c|c|}
\hline Budget & $\begin{array}{l}\text { Continuation of Horizon } 2020 \text { budget in } \\
\text { constant prices - } 15 \%\end{array}$ \\
\hline $\begin{array}{l}\text { Budget allocation across years, countries } \\
\text { and sectors }\end{array}$ & Horizon 2020 allocation \\
\hline Knowledge spillovers & $\begin{array}{l}\text { inter-sectoral and international spillovers } \\
\text { modelled using patent citation techniques } \\
\text { with no additional specificity for the } \\
\text { Framework Programme }\end{array}$ \\
\hline Direct leverage effect & $\begin{array}{l}\text { Direct leverage: } \\
\text { - Basic research: } 0 \\
\text { - National funding of applied R\&I: } 0.1 \\
\text { - EU funding of applied R\&I: } 0.15 \\
\text { Indirect leverage: firms keep their } \\
\text { investment effort constant in the long } \\
\text { term. }\end{array}$ \\
\hline Economic performance & $\begin{array}{l}\text { Higher performance of EU funding } \\
(+15 \%) \text { compared to national funding }\end{array}$ \\
\hline Financing & Reduction in public investment \\
\hline
\end{tabular}

by country and sector on the basis of the available empirical literature. Higher leverage and performance parameters for EU funding compared to national funding reflects the EU added value of the programme. The values for these parameters are supported by the existing quantified evidence on publications, patents and revenues from innovation. ${ }^{13}$

In order to assess the impact of the various changes in the design of Horizon Europe with respect to its predecessor programme, a set of scenarios have been assessed with the NEMESIS model either enhancing the impact of the programme, or reinforcing its openness. In each scenario, the changes envisaged in terms of the expected higher impact and wider openness were translated into variations of the values of certain parameters in NEMESIS. Therefore, different cases were considered, from low to high, by using ranges in the variation of the parameters. These ranges rely on plausible values found in the literature, with extreme values showing how impactful Horizon Europe can be under the most ambitious conditions. All these scenarios have been combined in the

13 For details on the points made in this paragraph, see European Commission (2017a) and Boitier et al. (2018). 
Table 7.2 Key departures from the assumptions in the "Continuation" scenario

\begin{tabular}{|c|c|c|}
\hline Changes for more impact & This assumes... & Range \\
\hline $\begin{array}{l}\text { Higher economic } \\
\text { performance }\end{array}$ & $\begin{array}{l}\text { Focus on R\&I with higher } \\
\text { economic impacts andd on } \\
\text { breakthrough innovations }\end{array}$ & $\begin{array}{l}\text { Higher performance of EU } \\
\text { funding compared to } \\
\text { national funding: }+0 \\
\text { (baseline) to }+5 \\
\text { percentage points }\end{array}$ \\
\hline $\begin{array}{l}\text { Lower knowledge } \\
\text { obsolescence }\end{array}$ & $\begin{array}{l}\text { More focus on } \\
\text { breakthrough knowledge }\end{array}$ & $\begin{array}{l}14 \% \text { to } 13 \% \text { obsolescence } \\
\text { rate compared to } 15 \% \text { in } \\
\text { the baseline. }\end{array}$ \\
\hline $\begin{array}{l}\text { Stronger complementarities } \\
\text { with other innovative assets }\end{array}$ & $\begin{array}{l}\text { More cross-technological } \\
\text { and cross-sectoral R\&I }\end{array}$ & $\begin{array}{l}5 \% \text { to } 10 \% \text { stronger than } \\
\text { in the baseline }\end{array}$ \\
\hline $\begin{array}{l}\text { Higher direct leverage of } \\
\text { private } R \& D\end{array}$ & $\begin{array}{l}\text { Betteraccess to finance of } \\
\text { innovative firms, especially } \\
\text { for SMEs }\end{array}$ & 0.1 (baseline) to 0.15 \\
\hline Changes for more openness & This assumes... & Range \\
\hline $\begin{array}{l}\text { Higher complementarities } \\
\text { with national support to } R \& D\end{array}$ & $\begin{array}{l}\text { Increased } \\
\text { complementarities } \\
\text { through partnerships }\end{array}$ & $\begin{array}{l}\text { Increased leverage for Basic } \\
\text { research: } 0.05 \text { to } 0.1 \\
\text { compared to } 0 \text { in the } \\
\text { baseline }\end{array}$ \\
\hline Stronger knowledge diffusion & $\begin{array}{l}\text { Facilitated knowledge } \\
\text { diffusion nationally } \\
\text { between the different } \\
\text { categories of research } \\
\text { organisations and/or } \\
\text { internationally }\end{array}$ & $\begin{array}{l}5 \% \text { to } 10 \% \text { stronger than } \\
\text { in the baseline }\end{array}$ \\
\hline
\end{tabular}

two "more impact" and "more openness" different scenarios. Table 7.2 summarises the changes relative to the "Continuation" scenario:

\subsubsection{Results}

The macroeconomic effects in NEMESIS shown in Fig. 7.3 can be divided into three main phases:

1. The investment phase: this is a 'demand phase' in which the dynamics are induced by the change in R\&D expenditures, with moderate impacts on innovation (as innovations only appear with a lag). This phase is hence dominated by the effect of the Keynesian multiplier embdedded in the model.

2. The innovation phase: the arrival of innovations (process and product) reduces the production costs of new products and/or raises the 


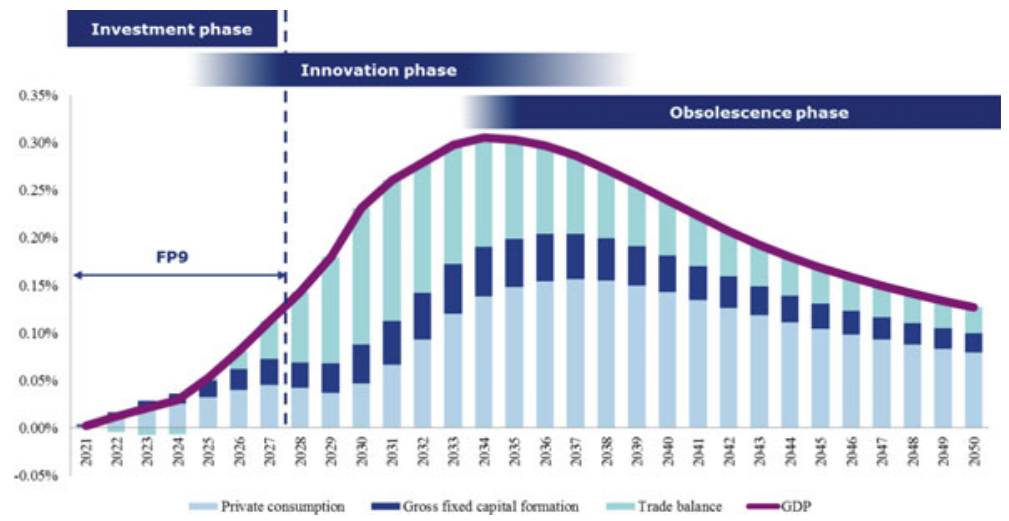

Fig. 7.3 GDP impacts under the "Continuation" of Horizon 2020 scenario (deviation in \% from a counterfactual scenario without Framework Programme) Source Boitier et al. (2018)

quality of existing ones, inducing an increase in both external and internal demands.

3. The obsolescence phase: progressively, newly achieved knowledge declines over time due to knowledge obsolescence. In the long-term, the economy returns back to the reference scenario.

Thus, Horizon Europe as defined in the "Continuation" scenario could provide an increase of EU GDP up to $+0.3 \%$ in 2035 . This gain of EU GDP is mainly driven by the private consumption that contributes to half of the EU GDP deviation in 2035, while the external balance contributes to $35 \%$. During the innovation phase, EU GDP gains are primarily driven by increasing market share of EU economy on global markets, rather than by the expansion of the internal market. Thereafter, productivity gains progressively spread throughout the European economy, inducing an increase in real wages that in turn reinforces the relative contribution of private consumption. In 2050, around two thirds of EU GDP deviation (i.e. $+0.13 \%$ ) can be ascribed to private consumption, with external balance explaining around $20 \%$ of EU GDP gains.

To summarise, the implementation of Horizon Europe, as defined in the "Continuation" scenario, delivers an increase of EU GDP by $€ 47$ billion (constant euro 2014) i.e. maximum $+0.3 \%$ in 2035 . And the 
cumulative EU GDP gain from 2020 to 2050 in the "Continuation" reaches $€ 850$ billion that is to say an average EU GDP raise of $€ 27$ billion per year.

Over the period of the Horizon Europe programme, up to a hundred thousand jobs are expected to be directly created in R\&D activities (see Figure 7.4). During this period, while the programme has a positive effect on jobs in the R\&D sector, the decrease in national public investment that is assumed in the scenario is mechanically accompanied by a comparable decrease in non R\&D-related jobs. The positive net indirect impact of the programme on jobs materialises starting at 2030, with the creation of more than two hundred thousand jobs after 2035, including more than eighty thousand highly-qualified jobs. From 2021 to 2050 , Horizon Europe could create, on average, more than one hundred thousand employments per year, which correspond to jobs in the research sector at the beginning, and then transform into high- and low-qualified jobs with time.

Turning to the impact of the changes envisaged in the design of the Horizon Europe programme, in the "more impact" scenario, the deviation in EU GDP, in comparison with "Continuation", could reach up to $+0.07 \%$ in 2040 , with on average, from 2021 to 2050 , a EU GDP deviation of $€ 7.3$ billion per year in 2014 constant euro (see Figure 7.5). In terms of employment, the gains are estimated at twenty eight thousand jobs yearly (average between 2021 and 2050). In the "more openness" scenario, the expected impact on EU GDP is lower and

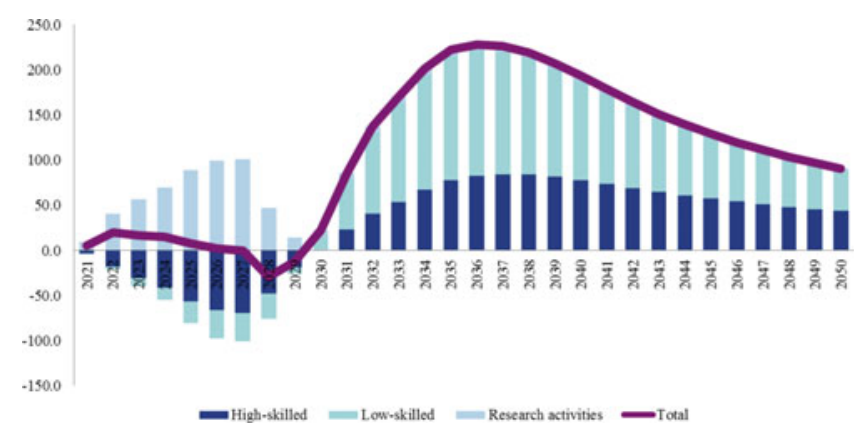

Fig. 7.4 Employment impact of the "Continuation" of Horizon 2020 (deviation in thousand jobs from a counterfactual scenario without Framework Programme) Source Boitier et al. (2018) 

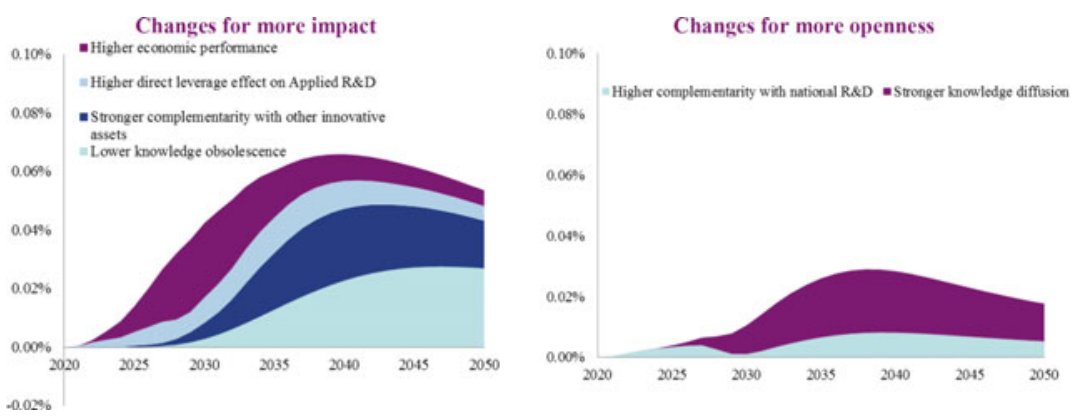

Fig. 7.5 Decomposition of total EU GDP impact into changes in the more impact and more openness scenarios (deviation in \% from the "Continuation" scenario of Horizon 2020) Scenarios based on highest values of parameter ranges. Source Boitier et al. (2018)

reaches a maximum of $+0.03 \%$ in 2040 . On average, from 2021 to 2050 , yearly EU GDP gains are about $€ 2.7$ billion whereas yearly employment gains are around nine thousand. Combining the "more impact" and "more openness" scenarios yields EU GDP gains of up to $0.1 \%$ in the most optimistic case, around $+€ 12$ billion per year, with an additional employment at EU level of a maximum of sixty seven thousand, in comparison with the "Continuation" scenario.

\section{REFERENCES}

Aghion, P., \& Howitt, P. (1998). Endogenous growth theory. Cambridge, MA: MIT Press.

Belderbos, R., \& Mohnen, P. (2013). Intersectoral and international R\&D spillovers. Working paper 2, EU 7th FP-SIMPATIC Project.

Bogliacino, F., \& Pianta, M. (2010). Innovation and employment: A reinvestigation using revised Pavitt classes. Research Policy, 39(6), 799-809.

Boitier, B., Le Mouël, P., Zagamé, P., Winjes, R., Mohnen, P., Ricci, A., Brozaitis, H., Espasa, J., \& Stanciauskas, V. (2018). Support for the assessment of socio-economic and environmental impacts (SEEI) of European ReI programmes: The case of Horizon Europe. Technical report, European Commission. Luxembourg: Publications Office of the European Union. ISBN 978-92-79-92736-2. 
Brécard, D., Chevallier, C., Fougeyrollas, A., Le Mouël, P., Lemiale, L., \& Zagamé, P. (2004). A 3\% ReDD: An analysis of the consequences using the Nemesis model. DG RTD: Technical report.

Brécard, D., Fougeyrollas, F., Le Mouël, P., Lemiale, L., \& Zagamé, P. (2006). Macro-economic consequences of European research policy: Prospects of the Nemesis model in the year 2030. Research Policy, 35(7), 910-924.

Bresnahan, T., \& Trajtenberg, M. (1995). General purpose technologies: Engines of growth. Journal of Econometrics, 65(1), 83-108.

Chevallier, C., Fougeyrollas, A., Le Mouël, P., \& Zagamé, P. (2006). A time to sow, a time to reap for the European countries: A macro-econometric glance at the RTD national action plans. Revue de l'OFCE, 97(5), 235-257.

Clark, K. B., \& Griliches, Z. (1984). Productivity growth and ReD at the business level: Results from the PIMS data base, Chapter 19, pp. 393-416.

Corrado, C., Haskel, J., Jona-Lasinio, C., \& Iommi, M. (2012).Intangible capital and growth in advanced economies: Measurement methods and comparative results (Working paper, EU 7th FP-INTAN-INVEST Project).

Corrado, C., Haskel, J., Jona-Lasinio, C., \& Iommi, M. (2014). Intagibles and industry productivity growth: Evidence from the EU. INTAN-Invest Paper: Technical report.

Damijan, J. P., Kostevc, C., \& Stare, M. (2014). Impact of innovation on employment and skill upgrading (SIMPATIC Working paper 7, SIMPATIC EU Project).

Delanghe, H., \& Muldur, U. (2007). Ex-ante impact assessment of research programmes: The experience of the European Union's 7th Framework Programme. Science and Public Policy, 34(3), 169-183.

European Commission. (2005). Annex to proposal for the Council and European Parliament decisions on the 7th Framework Programme (EC and Euratom)Impact assessment and ex-ante evaluation. Technical Report SEC(2005) 430, Commission Staff Working Paper.

European Commission. (2012). The Grand Challenge-The design and societal impact of Horizon 2020. Directorate-General for Research and Innovation: Technical report.

European Commission. (2017a). Taxes in Europe database v3.Database.

European Commission. (2017b). Assessment of the union added value and the economic impact of the EU framework programmes (FP7, Horizon 2020). Directorate-General for Research and Innovation, B-1049 Brussels.

European Commission. (2017c, May). In-depth interim evaluation of horizon 2020. Commission Staff Working Document. Directorate-General for Research and Innovation.

European Commission. (2018). Commission staff working document: Impact assessment. SWD(2018) 307 final, Part 2/3 . Brussels, 7.6.2018.

Eurostat. (2018a). Annual national accounts (ESA 2010). Database. 
Eurostat. (2018b). Annual sectors accounts. Database.

Eurostat. (2018c). Labor force survey. Database.

Eurostat. (2018d). Research and development statistics. Database.

Fougeyrollas, A., Le Mouël, P., \& Zagamé, P. (2010). Consequences of the 2010 $f p 7$ budget on European economy (Technical report, SEURECO-Demeter Working Paper).

Fougeyrollas, A., Le Mouël, P., \& Zagamé, P. (2011). Consequences of the fp7 2012 call on European economy and employment (Technical report, SEURECO-Demeter Working Paper).

Griliches, Z., \& Lichtenberg, F. (1984). R\&D and productivity growth at the industry level: Is there still a relationship?, Chapter 21 , pp. 465-502.

Ha, J., \& Howitt, P. (2007). Accounting for trends in productivity and R\&D: A schumpeterian critique of semi-endogenous growth theory. Journal of Money, Credit and Banking, 39(4), 733-774.

Hall, B. H. (2011). Innovation and productivity (Working Paper 17178, National Bureau of Economic Research).

Hall, B. H., Mairesse, J., and Mohnen, P. (2010). Measuring the returns to RerD, Volume 2 of Page ii, Chapter 24, pp. 1033-1082.

Hanel, P. (1994). R\&D, inter-industry and international spillovers of technology and the total factor productivity growth of manufacturing industries in Canada, 1974-1989. Cabiers de recherche, 94-04.

Harrison, R., Jaumandreu, J., Mairesse, J., \& Peters, B. (2014). Does innovation stimulate employment? A firm-level analysis using comparable micro-data from four European countries. International Journal of Industrial Organization 35(C), 29-43.

Le Mouël, P., Le Hir, B., Fougeyrollas, A., Zagamé, P., \& Boitier, B. (2016). Toward a macro-modelling of European innovation union: The contribution of NEMESIS model. In 9th Conference on Model-based Evidence on Innovation and Development (MEIDE) the 16-17 June 2016 in Moscow, Russia.

Link, A. N. (1982). A disaggregated analysis of industrial ReD: Product versus process $R \& D$.

OECD. (2017). Business enterprise RéD expenditure by industry.

Peters, B., Dachs, B., Dünser, M., Hud, M., Köhler, C., \& Rammer, C. (2014). Firm growth, innovation and the business cycle: Background report for the 2014 competitiveness report. Number 110577 in ZEW Expertises. ZEW-Zentrum für Europäische Wirtschaftsforschung.

PPMI. (2017). Assessment of the union added value and the economic impact of the EU framework programmes-Final report. Technical report.

Scherer, F. M. (1982). Interindustry technology flows and productivity growth. Review of Economics and Statistics, 64, 627-634.

Scherer, F. M. (1983). Concentration, R\&D and productivity change. Southern Economic Journal, 50, 221-225. 
Terleckyj, N. (1980). Direct and indirect effects of industrial research and development on the productivity growth of industries.

Timmer, M. P., Dietzenbacher, E., Los, B., \& Stehrer, R. (2015). An illustrated user guide to the world input-output database: The case of global automotive production. Review of International Economics, 23(3), 575-605.

Verspagnen, B. (1997). Estimating international technology spillovers using technology flow matrices. Review of World Economics, 133(2), 226-248.

Zagamé, P. (2010). The costs of a non-innovative Europe: What can we learn and what can we expect from the simulations works. SEURECO: Technical report.

Zagamé, P., Fougeyrollas, A., \& Le Mouël, P. (2012). Consequences of the 2013 $f p 7$ call for proposals for the economy and employment in the European union (Technical report, SEURECO-DEMETER working paper).

Open Access This chapter is licensed under the terms of the Creative Commons Attribution 4.0 International License (http://creativecommons.org/licenses/ by $/ 4.0 /$ ), which permits use, sharing, adaptation, distribution and reproduction in any medium or format, as long as you give appropriate credit to the original author(s) and the source, provide a link to the Creative Commons license and indicate if changes were made.

The images or other third party material in this chapter are included in the chapter's Creative Commons license, unless indicated otherwise in a credit line to the material. If material is not included in the chapter's Creative Commons license and your intended use is not permitted by statutory regulation or exceeds the permitted use, you will need to obtain permission directly from the copyright holder.

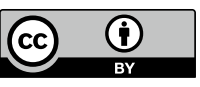

